\title{
Sri Lanka: 25 Million People and Implications, Population and Housing Projections 2012-2062 by W. Indralal de Silva and Ranjith de Silva (United Nations Population Fund, Colombo, 2015)
}

\author{
Reviewed by Sharmini de Alwis ${ }^{1}$ and Nimal Sanderatne ${ }^{2 *}$ \\ ${ }^{I}$ Former Additional Director of Statistics, Central Bank of Sri Lanka, Sri Lanka. \\ ${ }^{2}$ Former Director of Economic Research and Director of Statistics, Central Bank of Sri Lanka and former Senior Visiting Fellow, Post Graduate \\ Institute of Agriculture, University of Peradeniya, Peradeniya, Sri Lanka.
}

The publication Sri Lanka: 25 Million People and Implications, Population and Housing Projections 20122062, jointly authored by Prof. Indralal de Silva and Mr. Ranjith de Silva, presents comprehensive population and household projections for the period 2012-2062. It incorporates the latest information revealed in the Census of Population and Housing 2012 conducted by the Department of Census and Statistics. It covered the entire country after 31 years.

Such projections have been eagerly awaited by policy planners and researchers alike, ever since it became clear that the country's fertility rate had increased appreciably in the last $10-15$ years or so that was totally unexpected. The projections that had been made hitherto were, therefore, biased downwards, and policy recommendations made based on these projections became outdated.

The latest population projections in this publication are revealing. They are somewhat of a reversal of what was expected. The new projected population profile has significant implications for the country's economic and social policies. This book does not merely provide an update of the population projection, but also discusses a vast array of issues related to demography in Sri Lanka and abroad. These projections must be considered in the planning of health facilities, education and social welfare (particularly the care of the elderly).There are also serious implications for the public finances, labour force participation, retirement benefits, retirement age, housing demand and environmental issue, specially deforestation.

The book is organised under four key themes: population change until 2012 and reliability of projection results; projection of population 2012-2062; projection of households 2012-2062 and projected increase of population and its implications.

The publication provides projections of both population and households. Further the discussion under the theme "projected population increase and its implication" deals not only with the standard issues of demographic dividends and population ageing, but also with aspects such as future demand for housing, by providing estimations for the period 2012-62 and environmental degradation, which are of great relevance for policy formulation at present.

Trends in the historic growth in population are discussed under the theme population change till 2012. Available evidence of population levels prior to the holding of the first Census in 1871 is briefly presented while the growth in population, as revealed in the more systematic Census' conducted during the period spanning 1871 to 2012, is analysed in greater detail. Growth of the Sri Lankan population is discussed in detail during periods of the regions of Sinhalese Kings, Portuguese and Dutch (1505-1796), British (1796-1948), Postindependence and since independence. An interesting section under this theme is a comparison of the accuracy of past projections of researchers in Sri Lanka as well as the United Nations using quantitative methods. In this comparison, errors in total population and agesex structures of the past population projections are computed and evaluated with the observed values in Census of Population and Housing 2001 and 2012.

The central theme of this publication is the projection of the population 2012-2062. Here the cohort component method has been used to compute the population for a 50 year period with the base year information of the Census of Population and Housing 2012. 
Population growth is driven by three components: fertility, mortality and migration. Fertility trends are most crucial in population projections. Indeed, it was the totally unexpected increase in fertility above the replacement level in the last ten years that gave rise to an urgent need for revision of the population projection. According to the authors, Sri Lanka is unique among South Asian countries in experiencing this upturn in fertility. The projection of determinants of population growth is done under three scenarios; standard, high and low, with the standard projection representing the most plausible path. For the purpose of these population projections, the precise fertility rate assumed for each five year interval for each scenario is discussed and provided in tabular form. However, the assumed total fertility rates for the standard scenario starting with high value of 2.4, reaches the replacement level in 2027-32 and further declining. It reaches the replacement level early (202227) in low scenario and never reaches the replacement level in high scenario for the projected period.

With regard to mortality, measures relating to male and female life expectancy at birth have been used to examine the mortality transition in the country. This chapter also provides a comparison of Sri Lanka's life expectancy with other selected countries. Sri Lanka would reach a life expectancy level close to that of contemporary Japan by 2057-2062. To justify the mortality assumptions for projected period, it has been discussed changes in life expectancy, reasons for gender gap in life expectancy, non communicable diseases and health promotions. The assumptions with respect to mortality in each of the scenarios are also provided in detail in a table.

The projection of migration is preceded by a discussion on past migration trends in the different phases of the country's development and the nature of contemporary migration. The assumptions on net migration have been formulated both through past trends and consultations with officers of the Department of Immigration and Emigration and the Foreign Employment Bureau. Past trend of international migration, labour migration and its component, other types of outbound migration such as permanent and student migrations are considered to make assumptions on future migration trends. The assumed migration trend has been presented in tabular form for five year intervals.

The availability of assumptions on fertility, life expectancy and migration during the projected period in tabulated form is extremely useful for analysts. Whenever a deviation from these assumptions is observed in the future, users would realise that the projection has become outdated, and would in general be able to gauge the direction of the bias and accordingly make amendments to plans based on the population projection. Further, the projection on life expectancy would in itself be useful for the health sector and planning of geriatric care. Nevertheless, the assumed international migration patterns of male and female for the projected period are immensely helpful for migration analysts.

The projection of the population is presented in three scenarios: high, standard and low. The most plausible scenario is the standard population projection which is based on standard projections of the three components, fertility, mortality and migration. Under the standard projection, the population would reach 21.3 million in 2017 and 22.2 million by 2022 . The population would reach 25 million by 2042 and 25.8 million by 2062 . This implies that the population grows until 2062 and reaches stability between $25-26$ million. This is a significant departure from earlier projections that indicated population stability would be reached much earlier and the population would actually begin to decline in the early 2030s. This deviation is mainly due to the increase in fertility from below replacement level to above replacement level in the past ten years or so.

Since a large number of women will enter reproductive age in the next few years and the expected total fertility rate would be above the replacement level for some time, there is an in-built momentum for the growth of population in the next three to four decades. However, the rate of growth in the population will be on a declining trend and it is estimated that a near zero population growth rate would be attained after the year 2062.

The population projection is used to derive the components of population growth such as the crude birth rate, the crude death rate and the natural increase in the population for the period 2012-2062. According to a-priori expectations, there is a convergence between birth and death rates, with the natural increase in population steadily declining. The authors point out that as the number of the elderly grow, the higher mortality among them would override the conditions for declining mortality and result in an increase in the crude death rate. Authors have noticed that the trend in crude death rate is almost similar in all developed countries and some of the developing countries.

With regard to the gender balance, the projection implies that the sex ratio would favour females for the next 2 decades. However due to an expected improvement in male health in the next decade, and the elimination of some factors, such as the war that reduced male life expectancy in the past, male survival 
rates could improve. However, if male migrant rates exceed female migrant rates, the sex ratio would increase marginally in favour of males after about 2 decades. The rapid increasing trend in median age of the population (31 years in 2012 and 41.2 years in 2062) indicates how fast Sri Lankan population is ageing.

The shape of Sri Lanka's population pyramid has been changing rapidly over the years. This pyramid, which had a classical shape in 1981, changed into a pagoda like structure by 2012. The authors draw attention to the fact that during the interim period, the working age population had grown significantly. The proportion of children (below 15 years) had declined from 35 per cent in 1981 to 25 per cent in 2012. The book presents the projected population pyramids for 2022, 2042 and 2062 and it show major changes in age structure in coming decades. The declining fertility over the years is depicted by the progressive decline in the base of the pyramids.

The authors point out that children less than 15 years of age are the most susceptible to the assumptions made in the projections and their number will depend on the changes in the number of women in reproductive age and changes in child and infant mortality. An accurate estimate of the number of children is of much importance when making projections on expenditure on education. This number which stood at 5.1 million in 2012 will increase to 5.3 million in 2017, remain fairly static for the next ten years, and will fall once again to 5.1 million by 2032 . Thereafter, it would be on a declining trend and will drop to 4.4 million by 2062 . The earlier predictions expected a continuous decline in the child populations. In contrast to the child population, working age population (15-59) and elderly population (60+) will increase numerically throughout the projected period. It is highlighted that the proportion of elderly population takes an upward trend while child population is decreasing.

A projection of households has been made under Theme III, employing the household headship method. This data would be immensely useful to demographers and policy planners as well as for market projections as households are the main decision making unit and consumption unit in society. The discussion in this section covers the rate of increase in households and age and sex distribution of household heads, while a comparison is made between the structure of base year and end year projection of households. Characteristics of projected households on male and female heads is presented in table format. Further, changes in numbers and growth rate on population and household are presented in tabulated from and from graphically for the projected period.

Theme IV on the implications of population increase presents some interesting results and contains an important discussion relating to economic development. According to this new projection, the period of the demographic dividend spans from 1991 to 2019, when the working age population is taken to be 15-59 years, whereas it spans from 1991-2034 if the working age population is taken to be $15-64$. This is a slight increase in the period of the demographic dividend that what estimated under earlier prediction. However, it is emphasised that we have already passed the most attractive period of the demographic dividend which was around 2001.

The authors point out that many countries in East Asia experienced rapid economic growth during the period of their demographic dividend. Sri Lanka now has just a few more years in this regard and it is imperative that economic planners urgently identify growth sectors in the economy in order to generate sufficient economic opportunities for the influx of workers into the labour market during the rest of the period in which the demographic dividend prevails.

The issue of ageing is also discussed under this theme. According to the projection, the percentage of elderly (defined as those over 60 years) will increase from 12.4 per cent in 2012 to 25.8 per cent in 2062 . The growth rate in the elderly population will increase until 2022 and thereafter decline. The composition of the elderly would change over the years with the proportion of the "old" elderly ( 80 years and above) among the elderly increasing from 1.3 per cent in 2012 to 6.4 per cent in 2062. These figures are striking and have vast implications for geriatric health care services.

Two other issues that are touched under this theme are the demand for housing in the future and deforestation. Based on the projections of households, the required housing stock has been estimated until 2062. The demand for housing will increases due to changes in life style with tendency towards nuclear families and with the urbanisation occurring as work place differences. It might decrease due to an increase of ageing population as they need to part of a household. The authors conclude that unless Sri Lanka engages private or civil society organisations to build and upgrade houses and housing facilities, without the involvement of government, it would not be possible to meet the future demand for housing.

The brief section on deforestation discusses the depletion of forest cover in the past with the population increase and concludes that forest cover would definitely be reduced in the future with population growth as more land would be needed to meet the demand for food production and for development activities. 
This book is invaluable for policy planners and researchers who need to use population projections in their work. A large number of documents and research papers have been produced by national and international agencies using earlier population projections. Their conclusions and recommendations would need to be revisited in the light of these new population projections.

One of the predictions made based on earlier population projections was that the labour force would begin to decline from the mid 2030s. Manpower planners should take note that this is now not the case and the labour force would continue to expand in the first half of this century. Another prediction made was that the number of children would begin to decline continuously, so the required expenditure on educational infrastructure could be contained. However, according to this latest projection the child population will grow in 2017 and remain static until 2027 and thereafter decline. These are only two instances where implications based on previous population projections would have to be revised.

This book is valuable for many reasons mentioned earlier as well as because it contains useful comparisons of demographic variables between Sri Lanka and other countries. It has been written in simple non-technical language and all assumptions used have been clearly spelt out. The vast amount of information contained in the book is presented concisely in just over 100 pages. It should prove useful and interesting to policy planners, researchers, students and others from diverse academic backgrounds and those concerned with future of the country. 